\title{
Prenatal Dexamethasone Exposure Causes Loss of Neonatal Hypoxia Tolerance: Cellular Mechanisms
}

\author{
K. S. KAUFFMAN, F. J. SEIDLER, AND T. A. SLOTKIN \\ Department of Pharmacology: Duke L'niversity .Hedical Center. Durham. North (arolina 27710)
}

\begin{abstract}
Glucocorticoids promote lung cell differentiation and thus enhance surfactant synthesis in the management of neonatal respiratory distress syndrome. Because they also accelerate differentiation in other targets, glucocorticoids may compromise physiologic responses that operate through specialized fetal-neonatal mechanisms. The current study explores one such process, the capacity to maintain cardiac function during hypoxia, a critical function in light of the hypoxia associated with parturition and with neonatal respiratory distress. Pregnant rats were given $0.05,0.2$, or $0.8 \mathrm{mg} / \mathrm{kg}$ of dexamethasone on gestational $d 17,18$, and 19 , and the response to hypoxia was assessed in the offspring on the day after birth. Dexamethasone produced a dose-dependent impairment of survival during exposure to $5 \% \mathrm{O}_{2}(5 \mathrm{kPa} \mathrm{O})$ for $120 \mathrm{~min}$. ECG measurements showed that death in the dexamethasone-exposed animals was preceded by multiple arrhythmias and progressive atrioventricular conduction defects, terminating in cardiac arrest. Because maintenance of neonatal cardiac conduction during hypoxia depends on adrenergic mechanisms operating through adrenomedullary catecholamine release and actions at transiently expressed $\alpha_{2}$-receptors in the immature myocardium, we examined these mechanisms in control and dexamethasone-exposed neonates. Dexamethasone caused cardiac $\alpha_{2}-$ receptors to disappear prematurely, an effect that was selective for this receptor population because no comparable changes were seen in $\alpha_{1}$-receptors. Under normal circumstances, neonatal adrenomedullary responses to hypoxia operate in the absence of functional sympathoadrenal innervation, and cardiac-sympathetic innervation does not play a significant role; in a similar fashion, the dexamethasone-exposed animals did not display alterations in the functional state of sympathetic innervation of the adrenal medulla or heart at birth. Nevertheless, adrenomedullary catecholamine levels and the secretory response to hypoxia were significantly impaired by prenatal dexamethasone exposure, probably as a result of adrenal atrophy caused by the glucocorticoid. These results indicate that exposure to glucocorticoids in doses commensurate with their therapeutic actions on lung function evokes premature loss of the unique fetal-neonatal adrenergic mechanisms that are required to preserve cardiac function during hypoxia. ( $\mathrm{Pe}$ diatr Res 35: 515-522, 1994)
\end{abstract}

Glucocorticoid administration enhances cellular differentiation in fetal lungs, leading to induction of the enzymes needed

Received August 26. 1993; accepted December 8. 1993.

Correspondence: Dr. T. A. Slutkin. Box 3813, Department of Pharmacology: Duke University Medical Center. Durham. NC 27710

Supported by EPA CR-819585. for surfactant synthesis. This beneficial effect has led to widespread use of glucocorticoids by obstetricians and pediatricians to prevent or treat neonatal respiratory distress syndrome in infants born prematurely. However, enhanced cell differentiation comes at the expense of cell proliferation (1), leading to shortfalls in lung cell number, especially at the high doses typical of clinical steroid use (2). The compound effects of glucocorticoid exposure during development, sacrificing cell division in favor of differentiation, are also seen in systems other than the intended therapeutic target; in the nervous system, general impairment of cell acquisition is paired with selective promotion of development of a number of neurotransmitter systems, most notably catecholaminergic pathways (3-6). In the liver, targeting of catecholamine neurotransmission leads to a premature transition from fetal $\beta$-receptor-mediated control of glucose metabolism to the adult mechanism dominated by $\alpha_{1}$-receptors (7). Unlike the situation in the lung. where an accelerated time course of cell differentiation is beneficial in treating respiratory distress syndrome, the promotional effect on hepatic adrenergic mechanisms is detrimental. $\beta$-Adrenergic dominance in the fetal-neonatal period is adaptive for the carbohydrate-poor milk diet that requires gluconeogenesis; this metabolic process is effectively linked to $\beta$-receptors, with the appropriate stimulus supplied by a $\beta$-adrenergic agonist (epinephrine) released from the adrenal medulla in the absence of functional sympathetic innervation; glucose metabolism in adults, on the other hand, is controlled by $\alpha$-receptors stimulated by norepinephrine release from sympathetic neurons, producing glycogenolysis appropriate to the mature, carbohydrate-rich diet (8-12).

In general, then, it would be predicted that promotion of cell differentiation by glucocorticoid exposure will enhance physiologic function of systems that are inadequately developed in the fetus or neonate but will have deleterious effects on function when immature cells express a mechanism that is specialized to a specific maturational stage. Such a situation may exist in the developing heart, where both muscle structure and adrenergic function have properties that are uniquely different from those of the adult. First, the type of myosin heavy chain molecule found in the fetal rat heart is the $\beta$-form, characterized by low ATPase activity and a slow rate of shortening, attributes that are advantageous in the relatively $\mathrm{O}_{2}$-poor environment of fetal life and parturition (13-15). Expression of $\alpha$-myosin heavy chain, with high ATPase activity and a rapid rate of shortening, increases dramatically after birth, corresponding to the need for increased cardiac work in an $\mathrm{O}_{2}$-rich environment (16). Glucocorticoids accelerate the replacement of $\beta$-myosin heavy chain with the $\alpha$-form (17), a situation that could lead to a mismatch of cardiac work to existing energy availability. Second, as in the liver, adrenergic mechanisms in the fetal and neonatal heart differ substantially from those in adulthood. Cardiac sympathetic innervation is nonfunctional at birth, and hence adrenergic responses are mediated predominantly through circulating catecholamines derived from the adrenal medulla (12). Additionally, 
$\alpha_{2}$-adrenergic receptors are highly overexpressed in the immature heart, whereas they are virtually nonexistent in the adult (18). The importance of these two unusual features of adrenergic transmission can be revealed by the cardiac response to hypoxia, which is ordinarily well tolerated by the fetal or neonatal rat: either pharmacologic blockade of $\alpha_{2}$-receptors or interference with adrenal catecholamine secretion leads to cardiac arrest during hypoxia $(19,20)$.

Accordingly, the aspects of cardiac function during hypoxia that are specialized to the newborn are likely targets for adverse effects of glucocorticoids. In the current study, this hypothesis was evaluated by dexamethasone administration to pregnant rats in late gestation (d 17, 18, and 19) over a dose range that spans the threshold for promotion of cell differentiation as established by lung surfactant production and cardiac myosin isoform transitions $(17,21,22)$. Cardiac physiologic function and death during exposure to hypoxia were assessed on the day after birth. Finally, the mechanisms underlying dexamethasone-induced alterations in cardiac responses were evaluated, including effects on cardiac adrenergic receptor populations, adrenal catecholamine levels and output in response to hypoxia, and the status of sympathoadrenal and cardiac-sympathetic neuronal function.

\section{MATERIALS AND METHODS}

Animals and treatments. Timed pregnant Sprague-Dawley rats (Zivic-Miller Laboratories, Allison Park, PA) were housed individually and given free access to food and water. On gestational d 17,18 , and $19,0.05,0.2$, or $0.8 \mathrm{mg} / \mathrm{kg}$ of dexamethasone phosphate (Merck Sharp \& Dohme, Rahway, NJ) were administered s.c. to dams, whereas controls received equivalent volumes of isotonic saline vehicle $(1 \mathrm{~mL} / \mathrm{kg})$. This dose range has been shown previously to span the threshold for stimulation of lung enzymes involved in surfactant synthesis $(21,22)$. Experiments were carried out on the 1-d-old offspring. All experimental treatments and protocols involving live animals were approved by the Institutional Animal Care and Use Committee of Duke University Medical Center and conformed to guidelines set out in the NIH Guide for the Care and Use of Laboratory Animals.

Physiology. In hypoxic survival studies, pups from each treatment group were placed together in a sealed $20-\mathrm{L}$ plastic tub maintained at $37^{\circ} \mathrm{C}$ in a water bath. The container was ventilated with either prewarmed, humidified air or with $5 \mathrm{kPa} \mathrm{O}\left(5 \% \mathrm{O}_{2}\right)$ balanced with $\mathrm{N}_{2}$, at a flow rate of $7.5 \mathrm{~L} / \mathrm{min}$; these conditions produce rapid equilibration of neonatal blood gases to achieve an arterial $\mathrm{PO}_{2}$ of about $20 \mathrm{~mm} \mathrm{Hg}$ (23), comparable to that experienced during parturition (24). Pups were checked for survival at 30 -min intervals during the course of a 120-min hypoxic exposure, with cessation of breathing and presence of rigor mortis used as criteria. Electrocardiographic measurements were made on pups anesthetized intraperitoneally with $1.5 \mathrm{~g} / \mathrm{kg}$ of urethane (Sigma, St. Louis, MO), and then the animals were placed in the exposure chamber. Temperature was maintained at $37^{\circ} \mathrm{C}$ with a thermistor probe and infrared heating lamp. Needle electrodes were inserted into the limbs and recordings made with ECG lead II. Heart rate measurements were made at 1 -min intervals in room air until a constant baseline value was obtained. Air inflow was then changed to $5 \mathrm{kPa} \mathrm{O}$ plus $95 \mathrm{kPa} \mathrm{N}_{2}$, and recordings (heart rate, PR interval, and ECG wave form) were made at 30$\mathrm{s}$ to 5 -min intervals for up to $1 \mathrm{~h}$ of hypoxia. In an additional set of experiments to assess parasympathetic contributions to heart rate control, animals were given atropine $(5 \mathrm{mg} / \mathrm{kg}$ s.c., Sigma) after the initial stabilization period, and a new baseline heart rate was established. Air inflow was then changed over to $5 \mathrm{kPa} \mathrm{O}_{2}$, and recordings were made as before. Urethane is the anesthetic of choice for neonatal ECG studies because it does not alter adrenergic evoked responses of heart rate or blood pressure $(25,26)$; in the neonatal rat, anesthetic effects on cardiovascular reflexes or sympathetic neurotransmission would also not confound the measurements because peripheral sympathetic innervation is nonfunctional until the end of the 1st postnatal week (12).

Receptor binding assays. Pups were weighed and decapitated, after which hearts were dissected, weighed, frozen rapidly on dry ice, and stored at $-45^{\circ} \mathrm{C}$ until assayed. Tissues were later thawed and homogenized (Polytron, Brinkmann Instruments, Westbury, $\mathrm{NY}$ ) in 39 volumes of ice-cold buffer containing $145 \mathrm{~m} \mathrm{M} \mathrm{NaCl}$, $2 \mathrm{mM} \mathrm{MgCl}_{2}, 20 \mathrm{mM}$ Tris $(\mathrm{pH} 7.5)$ and sedimented at 40000 $\times g$ for $15 \mathrm{~min}$. The pellets were washed twice by resuspension (Polytron) in homogenization buffer followed by resedimentation. The final pellet was dispersed with a smooth-glass homogenizer fitted with a Teflon pestle, in four volumes (based on original wet weight of tissue) of $250 \mathrm{mM}$ sucrose, $2 \mathrm{mM} \mathrm{MgCl}$, $50 \mathrm{mM}$ Tris $(\mathrm{pH} \mathrm{7.5)}$, and the suspension was then used for ligand binding and for protein analysis (27). Use of this membrane preparation in developing rat tissues has been described previously $(28,29)$.

Radioligands were incubated with the tissue membrane preparations in a total volume of $250 \mu \mathrm{L}$. Incubations were stopped by dilution with $3 \mathrm{~mL}$ of ice-cold buffer, and the labeled membranes were trapped by rapid vacuum filtration onto Whatman $\mathrm{GF} / \mathrm{C}$ filters, which were then washed with additional buffer and counted by liquid scintillation spectrometry. $\alpha_{1}$-Receptor binding was determined with $2.2 \mathrm{nM}\left[{ }^{3} \mathrm{H}\right.$ ]prazosin (Du Pont Medical Products, Wilmington, DE; sp act, $19 \mathrm{Ci} / \mathrm{mmol})$. Duplicate aliquots of membrane preparation (containing approximately $0.18 \mathrm{mg}$ protein/assay) were incubated with radioligand in 10 $\mathrm{mM} \mathrm{MgCl}, 50 \mathrm{mM}$ Tris ( $\mathrm{pH} 7.5$ ) on ice for $50 \mathrm{~min}$. $\alpha_{2}$-Receptor binding was evaluated similarly with $2.5 \mathrm{nM}\left[{ }^{3} \mathrm{H}\right]$ rauwolscine (DuPont; sp act, $79 \mathrm{Ci} / \mathrm{mmol}$ ), approximately $0.44 \mathrm{mg}$ protein/ assay, and it was incubated for $20 \mathrm{~min}$ at room temperature. Nonspecific binding was defined as binding of radioligand in the presence of an excess concentration of a specific displacing agent, $5 \mu \mathrm{M}$ phentolamine (Ciba Pharmaceuticals, Summit. NJ) for both of the $\alpha$-receptor subtypes, again run in duplicate for each individual sample. Preliminary experiments were run to verify that equilibration occurred with the incubation times and temperatures chosen for each ligand. These conditions, including the subsaturating ligand concentrations, were chosen to match those in previous work $(11,29)$ with comparably small amounts of tissue and low receptor concentrations and where no information is available a priori as to whether differences will reside in the number of binding sites or in the receptor affinity.

Binding values obtained at a single, subsaturating ligand concentration, are capable of detecting alterations attributable either to changes in receptor equilibrium constant or maximum binding capacity but cannot distinguish between the two possible mechanisms. Accordingly, Scatchard analyses were conducted over a full range of subsaturating to saturating concentrations $(0.3-25 \mathrm{nM})$. Because of the difficulty in performing these assays on small amounts of tissue with low concentrations of receptors (see below), we limited these determinations to the receptor population that was affected significantly by dexamethasone $\left(\alpha_{2}-\right.$ receptors) and examined animals in just two groups, control and dexamethasone $0.8 \mathrm{mg} / \mathrm{kg}$. Under the subsaturating conditions described for the single ligand concentration experiments, nonspecific binding for $\alpha_{2}$-receptors was typically $60-70 \%$ of the total, and therefore for the Scatchard analyses we increased the assay membrane protein concentration by using up to 60 hearts per group for each preparation. Three separate preparations were made for each treatment group, and Scatchard analysis was run for each preparation, using duplicate or triplicate assays for total and nonspecific binding at each concentration. Results of the three preparations were then averaged for presentation.

Adrenal catecholamine levels and release. In the adrenal catecholamine studies, hypoxic exposures were conducted at $7 \mathrm{kPa}$ $\mathrm{O}_{2}$ so as to permit maximum survival rates in all treatment groups. Pups from each group were placed together in exposure chambers maintained at $37^{\circ} \mathrm{C}$ in a water bath and exposed to 
Table 1. Effects of prenatal dexamethasone treatment on maternal and litter characteristics*

\begin{tabular}{|c|c|c|c|c|c|}
\hline Measure & Control & Dex $-0.05 \mathrm{mg} / \mathrm{kg}$ & Dex- $0.2 \mathrm{mg} / \mathrm{kg}$ & $\mathrm{Dex}-0.8 \mathrm{mg} / \mathrm{kg}$ & $\begin{array}{c}\text { ANOVA } \\
\text { (all treatments) }\end{array}$ \\
\hline $\begin{array}{l}\text { Maternal weight gain }(\mathrm{g}) \text { from ges- } \\
\text { tational d } 17-19\end{array}$ & $30 \pm 2$ & $12 \pm 2 \dagger$ & $9 \pm 2 \dagger$ & $0 \pm 1 \dagger$ & $p<0.0001$ \\
\hline Percentage giving birth & 97 & 95 & 95 & 91 & NS \\
\hline Litter size & $11.7 \pm 0.5$ & $11.3 \pm 0.6$ & $10.9 \pm 0.5$ & $11.6 \pm 0.4$ & NS \\
\hline Dead pups/litter & $0.06 \pm 0.04$ & $0 \pm 0$ & $0.19 \pm 0.10$ & $0.61 \pm 0.16 \dagger$ & $p<0.0003$ \\
\hline Pup body wt (g) & $7.9 \pm 0.1$ & $7.5 \pm 0.1 \dagger$ & $7.0 \pm 0.1 \dagger$ & $5.8 \pm 0.1 \dagger$ & $p<0.0001$ \\
\hline Pup heart wt (mg) & $35.5 \pm 0.6$ & $34.8 \pm 0.6$ & $31.4 \pm 0.5 \dagger$ & $28.5 \pm 0.5 \dagger$ & $p<0.0001$ \\
\hline Heart/body wt (mg/g) & $4.47 \pm 0.05$ & $4.60 \pm 0.05$ & $4.45 \pm 0.05$ & $4.95 \pm 0.06 \dagger$ & $p<0.0001$ \\
\hline
\end{tabular}

* Data were obtained from 35-72 dams or litters and from $75-83$ pups in each treatment group; parametric values represent means \pm SEM. Weight results were combined for both males and females because there was no interaction of sex and treatment: values were compiled from no more than two pups from each litter (one male and one female). Dex, dexamethasone; ANOVA, analysis of variance.

† Significantly different from corresponding control value.

either prewarmed, humidified room air or $7 \mathrm{kPa} \mathrm{O}$ plus $93 \mathrm{kPa}$ $\mathrm{N}_{2}$ for a total of $90 \mathrm{~min}$. At the end of this period, animals were decapitated, the left adrenal glands were dissected immediately, and the tissues were homogenized in $1 \mathrm{~mL}$ of ice-cold $0.1 \mathrm{~N}$ $\mathrm{HClO}_{4}$ containing 300 ng of 3,4-dihydroxybenzylamine (Sigma) as an internal standard. Similarly, adrenal catecholamine release in response to hypoglycemia, which occurs by reflex activation of the splanchnic nerve (30), was tested by giving $20 \mathrm{IU} / \mathrm{kg}$ of insulin s.c. (Eli Lilly \& Co., Indianapolis, IN) or an equivalent volume of isotonic saline; $3 \mathrm{~h}$ later, pups were killed and the adrenal glands prepared for analysis as already described. When adrenal innervation is functional, this test produces release of $30-60 \%$ of the total content of catecholamines $(31,32)$.

Adrenal homogenates were sedimented at $26000 \times g$ for 10 min, and supernatant solutions were stored at $-20^{\circ} \mathrm{C}$. Catecholamines were first isolated by alumina adsorption, resuspended in $250 \mu \mathrm{L}$ of $0.2 \mathrm{~N}$ perchloric acid, and then analyzed by HPLC with electrochemical detection (33). All values were corrected for recovery of the internal standard.

Cardiac norepinephrine release. To assess whether dexamethasone alters the functional development of the cardiac-sympathetic axis, we assessed the reflex release of norepinephrine from cardiac sympathetic nerves with 2-deoxyglucose challenge (33). Pups were weighed and given $\alpha$-methyl- $p$-tyrosine methyl ester ( $300 \mathrm{mg} / \mathrm{kg}$ intraperitoneally; Sigma) to prevent norepinephrine resynthesis; this procedure is necessary when measuring cardiac norepinephrine release, but not adrenal catecholamine release, because of the greater rapidity of neuronal catecholamine biosynthesis $(33,34)$. Fifteen minutes after $\alpha$-methyl-p-tyrosine methyl ester administration, pups were injected with 2-deoxyglucose $(2 \mathrm{~g} / \mathrm{kg}$ intraperitoneally), which causes cellular glycopenia and thus evokes centrally mediated stimulation of cardiac sympathetic neurons (33), or with an equivalent volume of saline (3 $\mathrm{mL} / \mathrm{kg}$ ). Animals were decapitated $2.5 \mathrm{~h}$ later, and heart norepinephrine was determined as described for adrenal catecholamine analysis. Because of the low levels of norepinephrine present in neonatal rat heart, three to four hearts were pooled for each sample. When cardiac sympathetic innervation is functional, this challenge produces release of $25-50 \%$ of neuronal norepinephrine stores (33).

Data analy'sis. Data are presented as means \pm SEM. Statistical comparisons of the effects of dexamethasone on static measures were carried out with one-factor analysis of variance (control versus dexamethasone) with post hoc evaluation of each dexamethasone dosage group to the control using Dunnett's $t$ test. For studies involving short-term interventions of hypoxia or hypoglycemia, comparisons were carried out by two-way analysis of variance, considering factors of prenatal treatment (control versus dexamethasone) and the short-term test (room air versus low $\mathrm{O}_{2}$; saline versus insulin). Although some results are presented as percentages of control values, statistical tests were conducted only on the raw data. Nonparametric variables (incidence of death, proportion of pups showing arrhythmias during hypoxia, proportion of dams giving birth), were evaluated by Fisher's exact test. Scatchard plots of receptor binding were fitted by linear regression analysis. For all tests, significance was assumed at $p<0.05$.

\section{RESULTS}

In accordance with previous studies, dexamethasone administration resulted in a dose-dependent retardation of maternal weight gain and a higher incidence of neonatal death in the group exposed to the highest dose (Table 1). However, neither litter size nor the proportion of dams giving birth were affected; no difference in sex ratios was observed (data not shown). Neonatal body weights and heart weights were decreased by dexamethasone, but heart weight was spared relative to body weight, producing a relative cardiomegaly in the $0.8 \mathrm{mg} / \mathrm{kg}$ group. Again, these effects have been noted previously $(35,36)$.

Exposure to $2 \mathrm{~h}$ of $5 \mathrm{kPa} \mathrm{O}_{2}$ (balanced with $\mathrm{N}_{2}$ ) was well tolerated by the control neonates, resulting in only $2 \%$ mortality rate ( 1 out of 54 animals). In contrast, dexamethasone treatment produced a dose-dependent impairment of survival during hypoxia, with $6 \%$ mortality rate in the $0.05 \mathrm{mg} / \mathrm{kg}$ group (three of 50 animals, NS), $17 \%$ mortality rate at $0.2 \mathrm{mg} / \mathrm{kg}$ (cight of 48 animals, $p<0.002)$, and $26 \%$ mortality rate at $0.8 \mathrm{mg} / \mathrm{kg}(13$ of 50 animals, $p<0.0002$ ).

The typical ECG in control pups showed an early decrease in heart rate and lengthening of atrioventricular conduction time (increased PR interval) beginning at the onset of hypoxia and followed by stabilization at the lower rate and lengthened conduction time from about $30 \mathrm{~min}$ onward (Fig. 1). In general, normal sinus rhythm was maintained in the control pups, and the only notable change in ECG wave form was an elevation in the $T$ wave. Even in the few cases where control pups died during hypoxia, these animals exhibited normal ECG results immediately before the cessation of breathing. implicating respiratory arrest as the immediate cause of death.

Unlike the situation in control pups, ECG evaluations in the dexamethasone group indicated that the high rate of death during hypoxia was attributable to cardiac arrest (Fig. 1); in every case, death was preceded by arrhythmias, characterized by progressive atrioventricular conduction defects and grossly exaggerated $\mathrm{T}$ waves. Arrhythmic episodes in the group receiving the highest dose of dexamethasone occurred three to four times more frequently than in controls (Fig. 2). Control animals never exhibited more than one episode of arrhythmias during the hypoxic test period, whereas the dexamethasone-exposed animals often showed multiple episodes; in virtually every case, the animals showing multiple arrhythmias died after the second incidence of atrioventricular block.

Prenatal exposure to dexamethasone elicited differences in cardiac function during hypoxia even for animals in the treated group that did not die. First, the dexamethasone pups began with a significantly lower resting heart rate and an already prolonged 

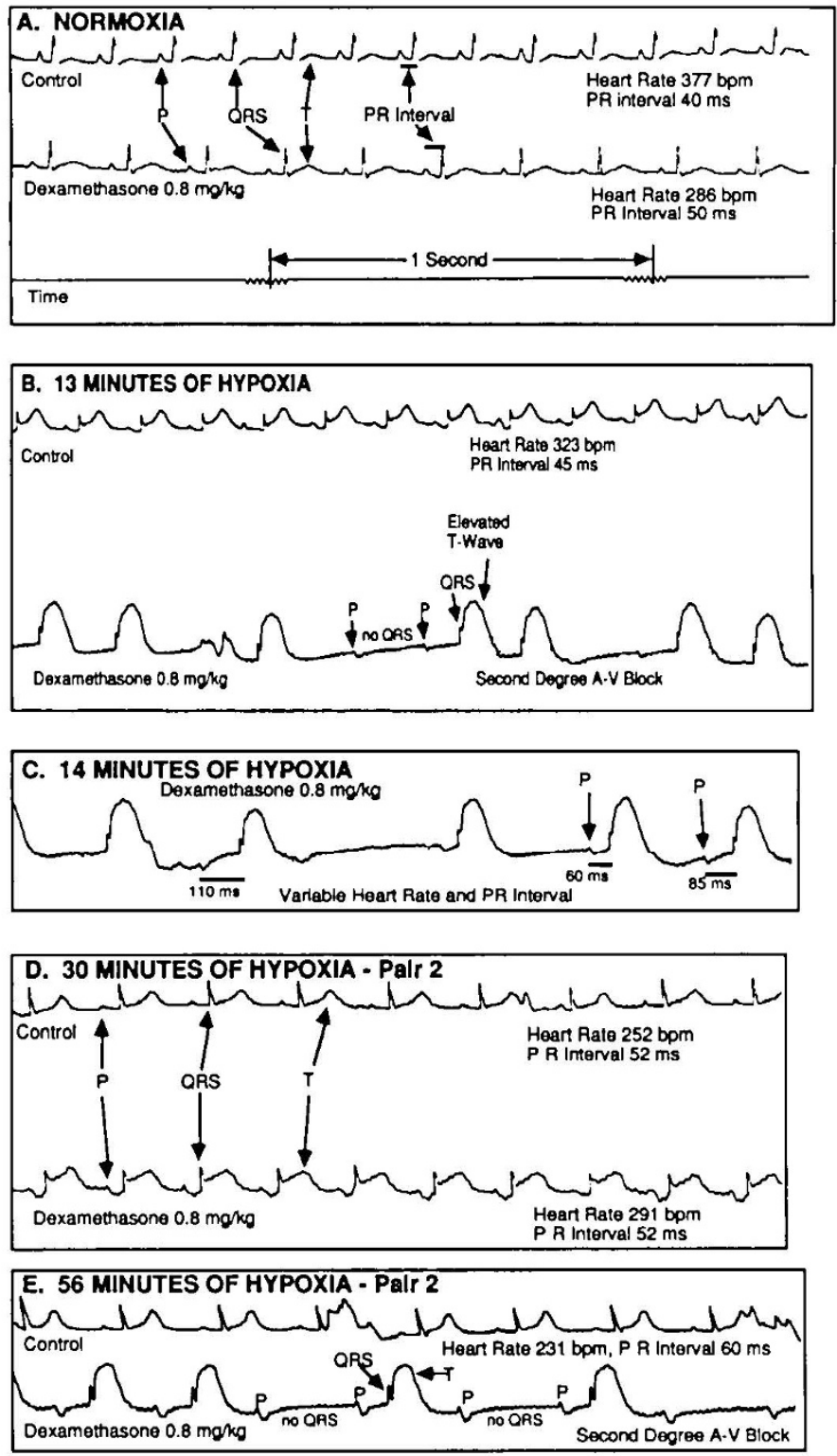

Fig. 1. Sample ECG recordings from control animals and animals exposed prenatally to $0.8 \mathrm{mg} / \mathrm{kg}$ of dexamethasone. $A$, Baseline readings show a slower heart rate in the dexamethasone group and a prolonged PR interval but maintenance of normal sinus rhythm and ECG wave form. $B$, After 13 min of $5 \mathrm{kPa} \mathrm{O}$ balanced with $\mathrm{N}_{2}$, the control animal shows a slowing of heart rate, a lengthening of the PR interval, and slight enhancement of the $T$ wave, the dexamethasone animal has gone into 2nd degree atrioventricular $(A-V)$ block, with two $\mathrm{P}$ waves required to elicit one $\mathrm{QRS}$ complex, and a grossly exaggerated $\mathrm{T}$ wave. $C$, Immediately thereafter $(14 \mathrm{~min})$, the heart rate in the dexamethasone animal has become extremely variable, and the PR interval changes from beat to beat; 2nd-degree block is still occasionally seen. $D$. In another pair of animals, by $30 \mathrm{~min}$ the control animal has again slowed its heart rate and lengthened its PR interval but has maintained a normal wave form; the dexamethasone animal has maintained the rate and interval at its normoxic values but shows an exaggerated T wave. $E$, At $56 \mathrm{~min}$ in this pair of animals, the control still has a normal ECG wave form with the reduced heart rate and lengthened $P R$ interval, whereas the dexamethasone animal has gone into 2 nd-degree atrioventricular block.

PR interval even under normoxic conditions (Table 2). With the commencement of hypoxia, as noted above, control animals produced a progressive lowering of heart rate that stabilized by $30 \mathrm{~min}$; however, the dexamethasone group reduced their heart rates much more slowly (Fig. 3). Similarly, whereas controls

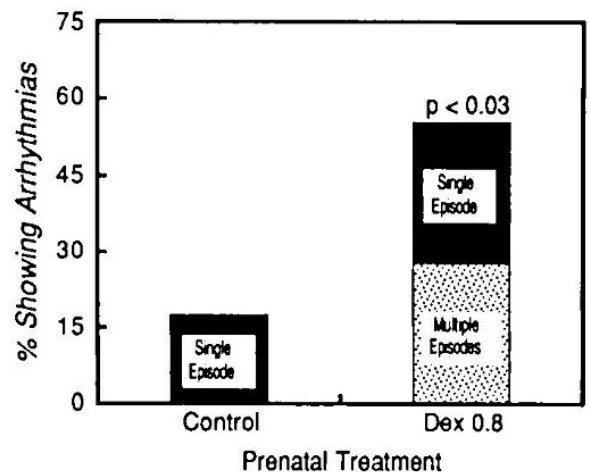

Fig. 2. Incidence of arrhythmias and multiple episodes of arrhythmias caused by breathing $5 \mathrm{kPa} \mathrm{O}$ in control animals and animals exposed to $0.8 \mathrm{mg} / \mathrm{kg}$ of dexamethasone $(D e x)$. Data were obtained from $16-18$ rats in each group; most of the animals experiencing multiple arrhythmic episodes died during the 60 -min period of hypoxia.

achieved a stable, prolonged PR interval during hypoxia (increase of $18 \pm 7 \mathrm{~ms}$ compared with normoxic values, measured $30 \mathrm{~min}$ into the hypoxic period; 16 animals), dexamethasone-exposed pups showed no such adjustment of conduction time (increase of $2 \pm 1 \mathrm{~ms}, 15$ animals, $p<0.05$ versus control). At the point of maximum difference between the control and dexamethasone groups ( $30 \mathrm{~min}$ into the hypoxic exposure), the controls displayed an average PR interval of $62 \mathrm{~ms}, 20 \%$ longer than the $52 \mathrm{~ms}$ seen in the dexamethasone group.

In the adult, cardiac slowing, lengthened atrioventricular conduction time, and arrhythmias are often a consequence of activation of the vagal parasympathetic innervation and can thus be prevented with a muscarinic blocking agent, such as atropine. Accordingly, we tested whether atropine would influence heart rate responses to hypoxia in control or dexamethasone-treated pups. Atropine failed to evoke a significant increase in resting heart rate in either group, indicating little or no tonic vagal control of heart rate (Fig. 4). Effects of atropine on heart rate during hypoxia were tested at the 30 -min exposure time, the point of maximum slowing in controls and of maximal separation of heart rate changes between the control and dexamethasone cohorts. Atropine did not prevent cardiac slowing in the controls, and the obtunded response was still apparent in the dexamethasone group.

We next concentrated on potential adrenergic mechanisms that could participate in the deleterious effects of dexamethasone on cardiac function during hypoxia. Because $\alpha_{2}$-adrenergic receptors are transiently overexpressed in developing heart (18) and are essential to maintaining conduction characteristics during hypoxia (20), we evaluated the effects of dexamethasone on expression of these receptors (Fig. 5). Measurement of $\left[{ }^{3} \mathrm{H}\right]$ rauwolscine binding to cardiac membrane preparations showed significant decrements of $25-30 \%$ at all doses of dexamethasone even when corrected for nonspecific growth inhibition by normalizing the values of membrane protein concentrations. Scatchard analysis conducted on membrane preparations from animals in the control and $0.8 \mathrm{mg} / \mathrm{kg}$ dexamethasone groups (Fig. 6) confirmed that the alterations in $\alpha_{2}$-receptor binding reflected changes in the number of receptors (maximum binding capacity), not receptor binding affinity (equilibrium constant). The selectivity toward $\alpha_{2}$-receptors was confirmed by parallel assessment of $\left[{ }^{3} \mathrm{H}\right]$ prazosin binding to $\alpha_{1}$-receptors, which are not transiently overexpressed during development. In contrast to the dexamethasone-induced decreases seen in $\alpha_{2}$-receptor binding, $\alpha_{1}$-receptors were not significantly affected overall and showed only slight decrements $(10-12 \%$, NS) even when the dose of dexamethasone was raised to growth-inhibiting levels (Fig. 5).

Adrenergic effects on $\alpha_{2}$-receptors regulating cardiac performance during neonatal hypoxia require release of adrenal catecholamines because cardiac sympathetic innervation is nonfunc- 
Table 2. Resting heart rate and PR interval in 1-d-old rats after prenatal exposure to dexamethasone*

\begin{tabular}{lccc}
\hline & Control & $\begin{array}{c}\text { Dexamethasone } \\
(0.8 \mathrm{mg} / \mathrm{kg})\end{array}$ & Significance \\
\hline Resting heart rate (beats/min) & $343 \pm 5$ & $311 \pm 6$ & $p<0.0001$ \\
PR interval $(\mathrm{ms})$ & $43.8 \pm 0.8$ & $50.1 \pm 0.7$ & $p<0.0001$ \\
\hline
\end{tabular}

* Data represent means \pm SEM from 16-18 rats in each treatment group.

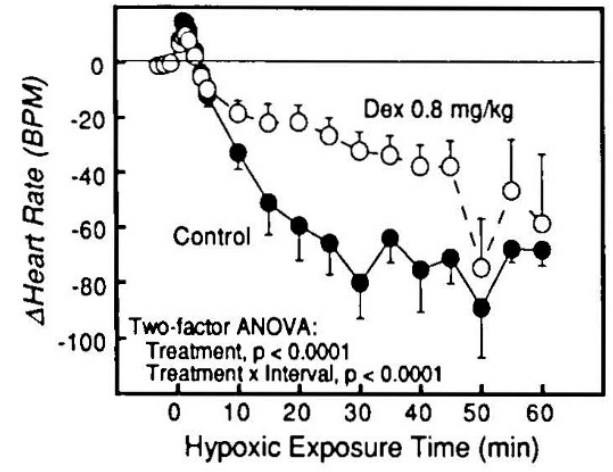

Fig. 3. Change in heart rate caused by breathing $5 \mathrm{kPa} \mathrm{O} \mathrm{O}_{2}$ in control animals and animals exposed to $0.8 \mathrm{mg} / \mathrm{kg}$ of dexamethasone $(D(x)$. Data represent means \pm SEM obtained from 17-18 pups in each group, but values do not include heart rates during periods of arrhythmias or values that were severely reduced just before death. $A N O \mathrm{I}^{\circ} \mathrm{A}$, analysis of variance.

tional at birth (12). Accordingly, we examined adrenal catecholamine levels and secretion of catecholamines during hypoxia. The total adrenal catecholamine content of the neonatal adrenal gland was significantly decreased by dexamethasone exposure $(p$ $<0.0001$ ), with a selective, dose-dependent deficit in the content of epinephrine without comparable effects on norepinephrine (Fig. 7). There was a parallel effect of dexamethasone on adrenal catecholamine secretion in response to hypoxia (Fig. 8). Epinephrine secretion in control animals exposed to $7 \mathrm{kPa} \mathrm{O}$ for $90 \mathrm{~min}$ amounted to $70 \mathrm{ng} /$ gland, approximately $20 \%$ of the entire content of the adrenal gland. Adrenomedullary secretion triggered by hypoxia was reduced by half in the animals exposed to the highest dose of dexamethasone.

The direct neonatal adrenal secretory response to hypoxia occurs without participation of splanchnic innervation, which does not become functional until the end of the 1st postnatal week (30). Accordingly, it was important to test whether the adverse effects of dexamethasone on adrenal responsiveness reflected alterations in the development of sympathoadrenal innervation, namely, premature innervation and loss of the auton-

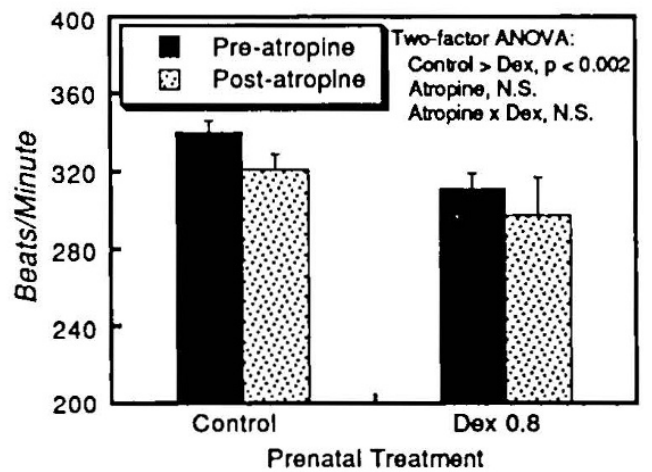

omous response. We therefore examined the reflex secretory response to insulin challenge, which requires functional connections from the CNS to the adrenal medulla (30). When innervation becomes functional, insulin challenge results in loss of $30-60 \%$ of adrenal catecholamines within the 3-h span of the test $(31,32)$. Control rats showed no significant secretory response to insulin (Table 3); animals in the high-dose dexamethasone group also showed no insulin response, although they again displayed a general reduction in basal catecholamine levels when compared with controls. Similarly, we tested whether the development of cardiac sympathetic innervation might have been accelerated by dexamethasone, using 2-deoxyglucose as the reflex metabolic stressor (33). As expected, 2-deoxyglucose produced no norepinephrine release from sympathetic nerves in 1d-old control rats: saline, $41 \pm 2 \mathrm{ng} / \mathrm{g}$ heart (15 animals): 2 deoxyglucose, $41 \pm 2 \mathrm{ng} / \mathrm{g}$ (15 animals; NS versus saline). Dexamethasone did not alter this pattern: saline, $40 \pm 3 \mathrm{ng} / \mathrm{g}(12$ animals); 2-deoxyglucose, $42 \pm 3 \mathrm{ng} / \mathrm{g}$ (12 animals; NS versus saline).

\section{DISCUSSION}

Results obtained in this study indicate that prenatal dexamethasone treatment adversely affects the neonate's ability to withstand hypoxia of the magnitude experienced during parturition $(23,24)$. A dose-dependent increase in mortality was seen during hypoxic challenge, with statistically significant effects obtained in both of the groups receiving doses of dexamethasone within the range for therapeutic use in treating respiratory distress $(0.2$ and $0.8 \mathrm{mg} / \mathrm{kg})(21,22)$. Our examination of the mechanisms underlying the loss of hypoxia tolerance indicates that no single effect of dexamethasone is responsible but rather that actions on multiple systems converge on cardiac function as the critical element.

The neonate's ability to withstand hypoxia involves unique, transiently expressed cellular events that are carefully coordinated to maintain cardiac rhythm in the face of a restricted energy supply. First, hypoxia causes secretion of catecholamines from the adrenal medulla into the circulation, a process that occurs despite the absence of functional neuronal connections between the CNS and the adrenal gland (19); indeed, with the

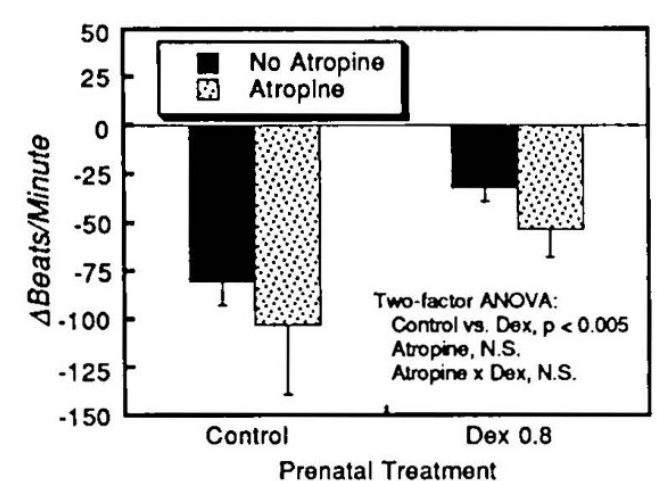

Fig. 4. Effects of atropine pretreatment on resting heart rate (left pancl) and on the heart rate response to hypoxia ( $5 \mathrm{kPa} \mathrm{O}_{2}$ for $30 \mathrm{~min}:$ right panel) in control animals and animals exposed to $0.8 \mathrm{mg} / \mathrm{kg}$ of dexamethasone ( $D(x)$ prenatally. Data represent means \pm SEM obtained from six to 18 animals in each group at each age. The main effect of dexamethasone alone was statistically significant with regard to both resting heart rate and the response to hypoxia. Atropine itself had no significant effect on either resting heart rate or on the response to hypoxia, nor did it reverse the lowering of resting heart rate or heart rate responses in the dexamethasone group (no significant interaction of dexamethasone and atropine). ANOYA, analysis of variance. 

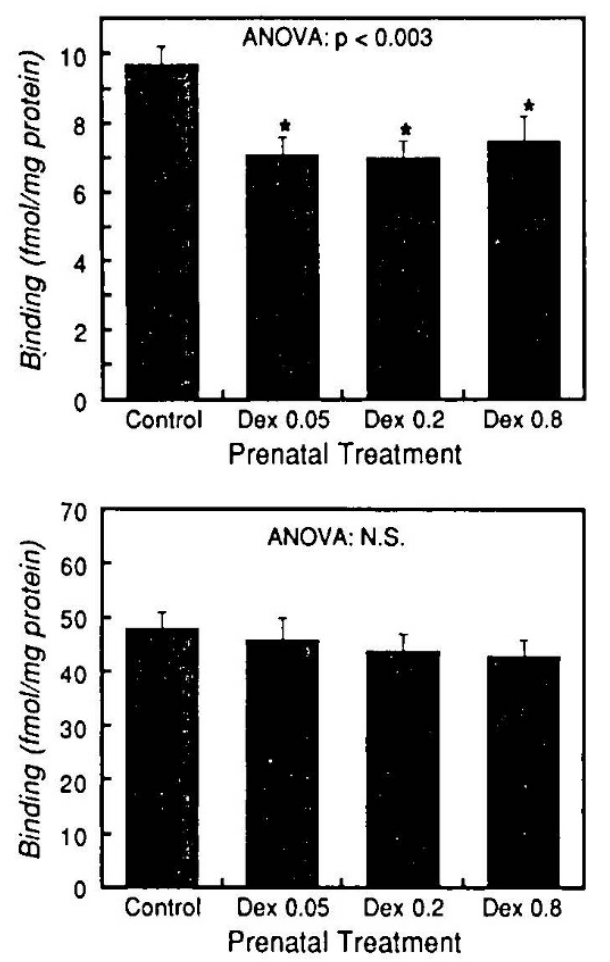

Fig. 5. Effects of prenatal dexamethasone $(D e x)$ exposure on cardiac $\alpha_{2}$-adrenergic receptor binding $(t o p)$ and $\alpha_{1}$-adrenergic receptor binding (bottom). Data are means \pm SEM obtained from 13-16 samples (two to five hearts per sample) in each treatment group. For $\alpha_{2}$-receptors, each individual dexamethasone group is also significantly different from controls. ${ }^{*}, p<0.01 . A N O V^{\prime} A$, analysis of variance.

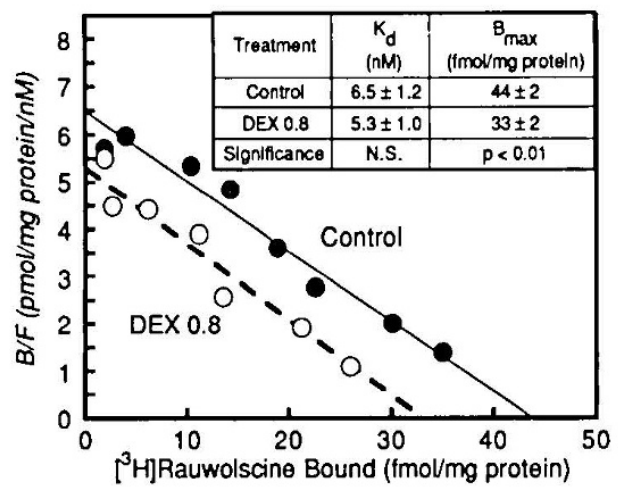

Fig. 6. Scatchard plots of $\alpha_{2}$-receptor binding isotherms from control rats and rats exposed to $0.8 \mathrm{mg} / \mathrm{kg}$ of dexamethasone (DEX) prenatally. Data points represent values averaged from three separate preparations (up to 60 hearts per preparation) in each treatment group. $B_{\max }$, maximum binding capacity.

onset of functional innervation, this unique ability is lost. The catecholamines then act on transiently expressed myocardial $\alpha_{2}-$ adrenergic receptors, a receptor population that is prominent in the fetus and neonate but not in the adult (18); these receptors affect cardiac pacemaker and conduction characteristics so as to maintain a normal sinus rhythm during hypoxia $(20,37)$, actions that are aided by the presence of the $\beta$-myosin heavy chain (16), a slow contractile protein that requires relatively less ATP than does the mature $\alpha$-form (13-15). It is thus the combined circumstance of nonneurogenic adrenomedullary responses, transiently expressed cardiac adrenergic receptors, and a fetal, energy-conservative myosin phenotype that renders the immature heart resistant to hypoxia of the magnitude that is experienced during parturition. Our results show that all of these processes are compromised by prenatal glucocorticoid administration.

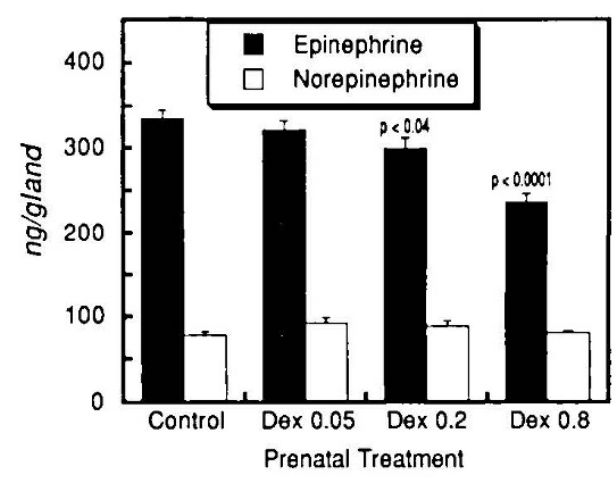

Fig. 7. Effects of prenatal dexamethasone $(D e x)$ exposure on adrenal catecholamine content. Data represent means \pm SEM obtained from 1547 pups in each treatment group. Analysis of variance across all treatment groups indicates highly significant differences for epinephrine $(p<$ 0.0001 ) but not norepinephrine (NS); the effects on epinephrine can be distinguished from the lack of effect on norepinephrine (interaction of treatment and amine, $p<0.0001$ ). Differences in epinephrine levels for individual treatment groups is control are indicated within the panel.

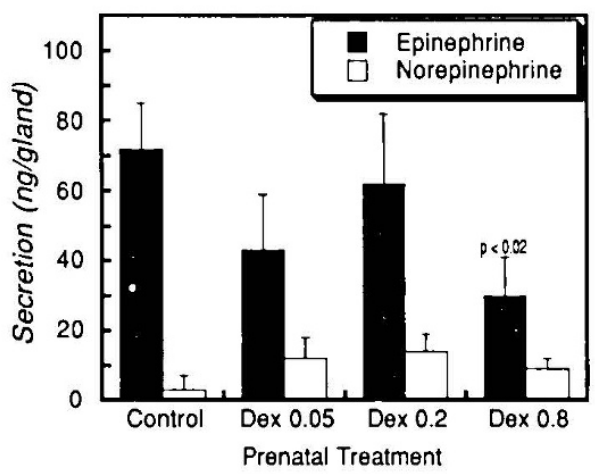

Fig. 8. Adrenal secretory response to hypoxia ( $7 \mathrm{kPa} \mathrm{O}_{2}$ for $\left.90 \mathrm{~min}\right)$, expressed as the difference between the resting levels, and the levels remaining in the adrenal glands at the end of the exposure period. Data represent means \pm SEM obtained from 17-55 animals in each treatment group. Dex, dexamethasone.

Table 3. Effects of insulin challenge on adrenal catecholamine content*

\begin{tabular}{lccccc}
\hline & \multicolumn{2}{c}{$\begin{array}{c}\text { Epinephrine } \\
\text { gland) }\end{array}$} & & \multicolumn{2}{c}{$\begin{array}{c}\text { Norepinephrine } \\
\text { (ng/gland) }\end{array}$} \\
\cline { 2 - 3 } \cline { 5 - 6 } Acute treatment & Control & Dex 0.8 & & Control & Dex 0.8 \\
\hline Saline & $354 \pm 19$ & $255 \pm 14$ & & $95 \pm 5$ & $90 \pm 6$ \\
Insulin (20 IU/kg) & $319 \pm 20$ & $226 \pm 11$ & & $93 \pm 5$ & $76 \pm 5$ \\
\hline
\end{tabular}

* Data represent means \pm SEM obtained from 19-20 animals in each group. Analysis of variance indicates a significant overall reduction in catecholamine levels (main effect, $p<0.0001$ ) caused by dexamethasone (Dex) but no significant response to insulin and no interaction of dexamethasone and insulin.

In control animals, the specialized adrenomedullary and cardiac mechanisms produced a slowing of heart rate and a lengthening of atrioventricular conduction time (increased PR interval) during hypoxia, measures that are conservative of cardiac work and energy use; nearly all of the controls thus maintained a relatively normal ECG wave form and sinus rhythm throughout the hypoxic period. In contrast, prenatal dexamethasone treatment led to loss of nearly $30 \%$ of the animals, with death attributable to cardiac arrhythmias and subsequent cardiac arrest. Even in the resting, normoxic state, dexamethasone-treated animals showed depressed heart rate and slowed atrioventricular conduction (lengthened PR interval); but unlike the controls, the dexamethasone-exposed animals took much longer to reduce 
their heart rate in response to hypoxia and showed no further lengthening of the PR interval until they actually proceeded into frank arrhythmias or complete 2 nd-degree atrioventricular block. None of these changes reflected alterations in parasympathetic function, as established by the inability of atropine to alter either the differences in the resting state or during hypoxia.

The particular set of hypoxia-induced ECG abnormalities in the dexamethasone group is identical with that seen when adrenergic mechanisms are obstructed in control rats during hypoxia (20). Accordingly, we next examined whether dexamethasone influences the unique adrenergic components of the hypoxia response in neonates. Indeed, the $\alpha_{2}$-adrenergic receptors that are uniquely overexpressed in the fetal-neonatal heart were significantly reduced even at the lowest dose of dexamethasone. This effect was selective in that no such actions occurred with $\alpha_{1}$-receptors, which are not overexpressed; previous work has also established that $\beta$-receptors are unaffected by this treatment $(38,39)$. $\alpha_{2}$-Receptor binding was reduced to a level that would ordinarily be found in animals 1 wk older (18), an age at which the specialized neonatal ability of the myocardium to maintain rhythm during hypoxia has been lost (20).

Although dexamethasone-induced alterations in cardiac receptor development participate in the loss of hypoxia tolerance, it is apparent that effects on receptors alone cannot account for the loss of adaptation; effects on receptors were already maximal at the lowest dexamethasone dose, whereas hypoxia-induced mortality showed a distinct increase with dose. Consequently, studies of adrenomedullary function were undertaken that showed that dexamethasone also interfered with catecholamine output in response to hypoxia, with a statistically significant effect seen at the highest dose of dexamethasone. The actions on catecholamine secretion in response to hypoxia were reflected in changes in basal adrenal catecholamine levels in the normoxic state, suggesting deleterious effects of dexamethasone on adrenomedullary development rather than interference with a specific secretory component. Because of the unique circulatory organization of the adrenal gland, with the venous effluent of the cortex providing the arterial supply of the medulla, the development and function of the catecholamine-containing cells of the adrenal medulla are closely intertwined with that of the adrenal cortex. High levels of adrenal corticosteroids provide the signal for the development of adrenomedullary phenylethanolamine- $N$-methyltransferase (40), the enzyme required for the synthesis of epinephrine from norepinephrine. Previous work has shown that, in animals treated with exogenous corticosteroids, feedback inhibition of the hypothalamus-pituitary-adrenal axis causes adrenocortical atrophy and attendant interference with adrenomedullary development $(41,42)$. In the current study, we found a specific, dose-dependent decrease in epinephrine in the adrenal glands of dexamethasone-treated neonates, commensurate with suppression of adrenocortical function. An attractive alternative hypothesis is that dexamethasone instead alters the timing of the onset of functional innervation of the adrenal medulla, a possibility suggested by findings that glucocorticoids can enhance cholinergic synaptogenesis in peripheral target tissues (43); however, this hypothesis was ruled out by the absence of a response to insulin, which evokes reflex activation of the splanchnic nerve to produce catecholamine secretion (30) in either the control or dexamethasone group. Similarly, alterations in the functional development of cardiac sympathetic nerves were ruled out with testing of reflex activation by 2 -deoxyglucose.

Accordingly, the insufficiency of adrenergic responsiveness in dexamethasone-exposed neonates, and their consequent inability to survive hypoxia, is a combined defect of inadequate adrenal catecholamine output and impairment of the specialized, $\alpha_{2}-$ adrenergic receptor population in the myocardium. Because glucocorticoids also accelerate cardiac cell differentiation, leading to premature replacement of the energy-conservative $\beta$-myosin heavy chain with $\alpha$-myosin (17), which has higher ATPase activity, these effects are superimposed on increased energy demand, compromising the neonate's ability to maintain cardiac function. Interference with the ability to survive hypoxia is particularly important in light of the current practice of administering corticosteroids to enhance lung function in preterm babies because these infants are likely to experience hypoxia as a result of respiratory immaturity. These results also raise questions about prenatal risk factors that evoke secretion of endogenous corticosteroids, including maternal stress or exposure to environmental toxicants. On the basis of our findings, we would predict that any factor producing a prolonged elevation of glucocorticoids in the maternal-fetal unit will lead to increased mortality during hypoxic episodes, including those associated with parturition, respiratory distress, or sleep apnea as a prelude to sudden infant death syndrome.

\section{REFERENCES}

1. Kauffman SL 1977 Proliferation, growth. and differentiation of pulmonary epithelium in fetal mouse lung exposed transplacentally to dexamethasone. Lab Invest 37:497-501

2. Slotkin TA. Seidler FJ, Kavlock RJ, Bartolome JV 1991 Fetal dexamethasone exposure impairs cellular development in neonatal rat heart and kidney: effects on DNA and protein in whole tissues. Teratology 43:301-306

3. Slotkin TA, Lappi SE. Tayyeb MI, Seidler FJ 1991 Dose-dependent glucocorticoid effects on noradrenergic synaptogenesis in rat brain: ontogeny of ['H] desmethylimipramine binding sites after fetal exposure to dexamethasone. Res Commun Chem Pathol Pharmacol 73:3-19

4. Slotkin TA, Lappi SE, McCook EC, Tayyeb MI, Eylers JP. Seidler FJ 1992 Glucocorticoids and the development of neuronal function: eflects of prenatal dexamethasone exposure on central noradrenergic activity. Biol Neonate $61: 326-336$

5. Uno H, Lohmiller L, Thieme C, Kemnitz JW, Engle MJ, Roecker EB, Farrell PM 1990 Brain damage induced by prenatal exposure to dexamethasone in fetal rhesus macaques. 1. Hippocampus. Dev Brain Res 53:157-167

6. Carlos RQ, Seidler FJ, Slotkin Ta 1992 Fetal dexamethasone exposure alters macromolecular characteristics of rat brain development: a critical period for regionally selective alterations? Teratology 46:45-59

7. Huff RA, Seidler FJ, Slotkin TA 199I Glucocorticoids regulate the ontogenetic transition of adrenergic receptor subtypes in rat liver. Life Sci 48:1059-1066

8. Aggerbeck M, Guellarn G, Hanoune J 1980 Adrenergic receptor of the $x_{1}$ subtype mediates the activation of the glycogen phosphorylase in normal rat liver. Biochem Pharmacol 29:643-645

9. Morgan NG, Blackmore PF, Exton JH 1983 Age-related changes in the control of hepatic cyclic AMP levels by $\alpha_{1}$ and $\beta_{2}$ adrenergic receptors. J Biol Chem 258:5103-5109

10. McMillian MK. Schanberg SM, Kuhn CM 1983 Ontogeny of rat hepatic adrenoceptors. J Pharmacol Exp Ther 227:181-186

11. Slotkin TA 1986 Development of the sympathoadrenal axis. In: Gootman PM (ed) Developmental Neurobiology of the Autonomic Nervous System. Humana Press, Clifton. NJ, pp 69-96

12. Slotkin TA 1986 Endocrine control of synaptic development in the sympathetic nervous system: the cardiac-sympathetic axis. In: Gootman PM (ed) Developmental Neurobiology of the Autonomic Nervous System. Humana Press. Clifton, NJ. pp 97-133

13. Lompré AM. Mercadier JJ. Wisnewsky C. Bouveret P. Pantaloni C. d'Albis A Schwartz K 1981 Species- and age-dependent changes in the relative amounts of cardiac myosin isoenzymes in mammals. Dev Biol 84:286-290

14. Schwartz K, LeCarpentier Y, Martin JL, Lompré AM, Mercadier JJ, Swynghedauw B 1981 Myosin isoenzymic distribution correlates with speed of myocardial contraction. J Mol Cell Cardiol 13:1071-1075

15. Ebrecht G, Rupp H, Jacob R 1982 Alterations of mechanical parameters in chemically skinned preparations of rat myocardium as a function of isoenzyme pattern of myosin. Basic Res Cardiol 77:220-234

16. Briggs MM. Seidler FJ, Slotkin TA, Schachat FH 1992 Ontogenetic transition of cardiac myosin heavy chain isoforms in rat ventricle: effects of fetal exposure to $\beta$-adrenergic agonists or antagonists. J Dev Physiol 17:201-206

17. Bian X. Briggs MM, Schachat FH, Seidler FJ, Slotkin TA 1992 Glucocorticoids accelerate the ontogenetic transition of cardiac ventricular myosin heavychain isoform expression in the rat: promotion by prenatal exposure to a low dose of dexamethasone. J Dev Physiol 18:35-42

18. Lin W, Seidler FJ, McCook EC, Slotkin TA 1992 Overexpression of $\alpha_{22}$ adrenergic receptors in fetal rat heart: receptors in search of a function. J Dev Physiol 17:183-187

19. Seidler FJ, Slotkin TA 1985 Adrenomedullary function in the neonatal rat: responses to acute hypoxia. J Physiol 358:1-16

20. Seidler FJ, Brown KK. Smith PG. Slotkin TA 1987 Toxic effects of hypoxia

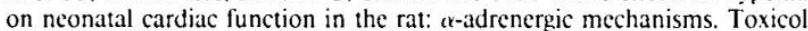
Lett 37:79-84

21. Anderson GG, Lamden M. Cidlowski JA. Ashikaga T 1981 Comparative pulmonary surfactant-inducing effect of three corticosteroids in the nearterm rat. Am J Obstet Gynecol 139:562-564

22. Kudlacz EM, Navarro HA. Slotkin TA 1989 Phosphatidic acid phosphatase in neonatal rat lung: effects of prenatal dexamethasone or terbutaline treatment 
on basal activity and on responsiveness to beta-adrenergic stimulation. J Pharmacol Exp Ther 250:236-240

23. Sylvia AL, Seidler FJ, Slotkin TA 1989 Effect of transient hypoxia on oxygenation of the developing rat brain: relationships among hxmoglobin saturation, autoregulation of blood flow and mitochondrial redox state. J Dev Physiol 12:287-292

24. Faber JJ, Anderson DF, Morton MJ, Parks CM, Pinson CW, Thornburg KL, Willis DM 1985 Birth, its physiology, and the problems it creates. In: Jones CT. Nathanielsz PW (eds) The Physiological Development of the Fetus and Newborn. Academic Press, London, pp 371-380

25. Mills E. Bruckert JW, Smith PG 1986 Development of adrenergic and nonadrenergic pressor mechanisms in rats sympathectomized from birth. J Pharmacol Exp Ther 238:1014-1020

26. Mills E, Smith PG 1986 Mechanisms of adrenergic control of blood pressure in developing rats. Am J Physiol 250:R188-R192

27. Lowry OH, Rosebrough NJ, Farr AL, Randall R 1951 Protein measurement with the Folin phenol reagent. J Biol Chem 193:265-270

28. Witkin RM, Harden TK 1981 A sensitive equilibrium binding assay for soluble $\beta$-adrenergic receptors. J Cyclic Nucleotide Res 7:235-246

29. Slotkin TA, Kudlacz EM, Lappi SE, Tayyeb MI, Seidler FJ 1990 Fetal terbutaline exposure causes selective postnatal increases in cerebellar aadrenergic receptor binding. Life Sci 47:2051-2057

30. Seidler FJ, Slotkin TA 1986 Ontogeny of adrenomedullary responses to hypoxia and hypoglycemia: role of splanchnic innervation. Brain Res Bull 16:11-14

31. Slotkin TA 1973 Maturation of the adrenal medulla-II: content and properties of catecholamine storage vesicles of the rat. Biochem Pharmacol 22:20332044

32. Slotkin TA, Kirshner N 1973 All-or-none secretion of adrenal medullary storage vesicle contents in the rat. Biochem Pharmacol 22:205-219

33. Seidler FJ, Slotkin TA 1981 Development of central control of norepinephrine turnover and release in the rat heart: responses to tyramine, 2-deoxyglucose and hydralazine. Neuroscience 6:2081-2086

34. Bartolomé J, Slotkin TA 1976 Effects of postnatal reserpine administration on sympathoadrenal development in the rat. Biochem Pharmacol 25:15131519

35. Sicard RE, Werner JC 1992 Dexamethasone induces a transient relative cardiomegaly in neonatal rats. Pediatr Res 31:359-363

36. Bian X, Seidler FJ. Slotkin TA 1993 Fetal dexamethasone exposure interferes with establishment of cardiac noradrenergic innervation and sympathetic activity. Teratology 47:109-117

37. Yatani A. Okabe K. Cordina J. Birnbaumer L. Brown A 1990 Heart rate regulation by $\mathrm{G}$ proteins acting on the cardiac pacemaker channel. Science 249:1163-1166

38. Bian X. Seidler FJ, Olsen C, Raymond JR. Slotkin TA 1993 Effects of fetal dexamethasone exposure on postnatal control of cardiac adenylate cyclase: $\beta$-adrenergic receptor coupling to $\mathrm{G}_{\mathrm{s}}$ regulatory protein. Teratology 48:169177

39. Navarro HA, Kudlacz EM. Slotkin TA 1991 Control of adenylate cyclase activity in developing rat heart and liver: effects of prenatal exposure to terbutaline or dexamethasone. Biol Neonate 60:127-136

40. Ciaranello RD, Jacobowitz D, Axelrod J 1973 Effect of dexamethasone on phenylethanolamine $N$-methyltransferase in chromaffin tissue of the neonatal rat. J Neurochem 20:799-805

41. Lau C. Slotkin TA 1981 Maturation of sympathetic neurotransmission in the rat heart. VII. Suppression of sympathetic responses by dexamethasone. J Pharmacol Exp Ther 216:6-11

42. Sorimachi M 1977 Impaired maturation of pre-synaptic cholinergic nerve terminals in the superior cervical ganglia after administration of guanethidine and dexamethasone. Jpn J Pharmacol 27:629-634

43. Puro DG 1983 Glucocorticoid regulation of synaptic development. Dev Brain Res 8:283-290 